University of California, Hastings College of the Law UC Hastings Scholarship Repository

Faculty Scholarship

2011

\title{
The Potential of Shared Decision Making to Reduce Health Disparities
}

Jaime S. King

UC Hastings College of the Law, kingja@uchastings.edu

Mark H. Eckman

Benjamin W.Moulton

Follow this and additional works at: http://repository.uchastings.edu/faculty_scholarship

Part of the Medical Jurisprudence Commons

\section{Recommended Citation}

Jaime S. King, Mark H. Eckman, and Benjamin W. Moulton, The Potential of Shared Decision Making to Reduce Health Disparities, 39 Journal of Law 30 (2011).

Available at: http://repository.uchastings.edu/faculty_scholarship/326 


\title{
UNIVERSITY of CALIFORNIA HASTINGS COLLEGE OF THE LAW
}

\section{Faculty Publications}

UC Hastings College of the Law Library

\author{
Author: Jaime S. King \\ Source: $\quad$ Journal of Law, Medicine \& Ethics \\ Citation: $\quad 39$ J.L. Med. \& EthICS 30 (2011). \\ Title: $\quad$ The Potential of Shared Decision Making to Reduce Health Disparities
}

Originally published in JOURNAL OF LAW, MEDICINE \& ETHICS. This article is reprinted with permission from Journal OF LAW, MEDICINE \& ETHICS and American Society of Law, Medicine \& Ethics. 


\title{
The Potential of Shared Decision Making to Reduce Health Disparities
}

\author{
Jaime S. King, Mark H. Eckman, and Benjamin W. Moulton
}

$\mathrm{C}$ urrent methods of obtaining an informed consent leave much to be desired. Patients rarely read consent forms or understand all of the risks, benefits, or alternatives associated with their treatment. ${ }^{1}$ Evaluating the advantages and disadvantages of treatment options often presents a more significant challenge for patients with lower levels of health literacy. This article reviews the evidence of shortcomings in our informed consent system and then explores the potential for a new approach to engage patients at all levels of health literacy in their treatment decisions. Specifically, the article will examine the potential of shared decision-making (SDM) to bridge gaps in knowledge, increase patient adherence to treatment, and improve health outcomes in low health literacy patient populations. Leveling barriers to treatment information for disadvantaged populations should be a public health imperative, especially if it can be shown to improve health outcomes and reduce health disparities.

In general, physicians have legal and ethical obligations to obtain an informed consent from patients to engage in treatment. With notable exceptions for patients incapable of providing consent, informed consent typically occurs in three steps: (1) a brief conversation with the physician regarding the preferred treatment; (2) the provision of a form that lists the risks of treatment; and (3) execution of the consent

Jaime S. King, J.D., Ph.D., is an Associate Professor of Law at the University of California Hastings College of the Law. Mark H. Eckman, M.D., M.S., FACP, is in the Division of General Internal Medicine and Center for Clinical Effectiveness at the University of Cincinnati. Benjamin W. Moulton, J.D., M.P.H., is a Lecturer in Health Law at Harvard School of Public Health and a Senior Legal Advisor at the Foundation for Informed Medical Decision Making. form by the patient. Under this system, patients rarely make a truly informed decision. A review of over 540 informed consent forms at 157 randomly selected hospitals found that informed consent documents had limited informational value for the general patient population. ${ }^{2}$ More concerning, a study of surgical patients found that over $70 \%$ failed to read the consent form and did not comprehend the risks of surgery. ${ }^{3}$ This system also poorly elicits patient preferences regarding the relative risks and benefits of alternative treatment options.

A more recent study at the University of Michigan, known as the DECISIONS study, provides significant clues about the epidemiology of decision-making in the United States. ${ }^{4}$ Through a nationwide random digit dial survey, DECISIONS researchers conducted telephone interviews with 2,575 participants, age 40 and older, to examine whether patients received basic information about their options prior to making health-related decisions.

The DECISIONS study revealed a pattern of inadequate medical decision-making that spanned the country and nine common medical conditions. In the last two years, $56 \%$ of survey participants discussed medication changes, $72 \%$ discussed cancer screening, and $16 \%$ discussed surgery with their providers. A panel of experts articulated five essential facts deemed critical to decision making for each of the conditions surveyed. Researchers found that many patients were "lacking knowledge of key facts needed to make informed choices." ${ }^{5}$ For eight of the nine decisions, less than $50 \%$ of patients could answer more than one basic question about their treatment. Furthermore, patients reported that physicians asked them for their preferences less than one-third of the time. These 
findings were more robust for those with lower education levels. ${ }^{6}$

Interestingly, the DECISIONS survey also found that many patients understand much less than they think they do. ${ }^{7}$ Despite lower knowledge scores, patients with less education and income felt extremely well informed with respect to medication and screening decisions. The researchers suggested that this could be because some patients do not understand the information related to the treatment or the limits of their knowledge. The results imply that that the failings of our current informed consent model weigh most heavily on patients who need the information the most.

Alternative models of providing information to patients should be explored to improve patient comprehension of medical decisions and their ability to actively participate in treatment. SDM has received a great deal of attention. It is "a process in which the physician shares with the patient all relevant risk and benefit information on all treatment alternatives and the patient shares with the physician all relevant personal information that might make one treatment or side effect more or less tolerable than others." 8 Both parties use this information to come to a decision. Often as part of SDM, providers offer patients the opportunity to review a decision aid. Decision aids commonly come in pamphlet or video form and provide the patient with detailed information on the risks and benefits of the treatment alternatives for the condition in question (e.g., benign prostatic hypertrophy, obesity, or breast cancer). Decision aids offer patients the opportunity to (1) learn about their disease or condition and their treatment options at home; (2) review information multiple times on their own or with family and friends; and (3) be more prepared to discuss their options with their physician. In addition, many decision aids prompt patients to think about their personal preferences and values for different risks, benefits, and health conditions that should play a part in their decision.

Empirical research demonstrates that SDM with decision aids can significantly improve a patient's decision-making. The Cochrane Review conducted 55 trials of decision aids addressing 23 different screening or treatment decisions. The research concluded that SDM with decision aids improves patient knowledge of the risks and benefits of treatment, the accuracy of risk perceptions, patient comfort with decisions, and participation in decision-making, as well as lessens the number of patients who remain undecided concerning their treatment. ${ }^{9}$ These beneficial effects are also seen in studies examining segments of the population with the lowest health literacy. ${ }^{10}$
Moreover recent pilot studies also suggest that improving informed consent practices for patients with low health literacy may have the collateral benefit of improving health outcomes and, correspondingly, the public's health..$^{11}$ The possible link between SDM and improved health outcomes is derived from greater patient activation in their care. In general, results from studies investigating whether SDM improves overall health outcomes have been mixed. A 2006 Cochrane Review of decision aids found that while using decision aids increased patient activation, there was no correlation between use of the aids and health outcomes..$^{12}$ However, a number of other studies found linkages between increased patient activation in decision-making and health outcomes. ${ }^{13}$ For example, a recent pilot study found that patients at a senior center who watched three or more decision aid videos on chronic care had significantly higher patient activation scores at both 12 weeks and at 6 months than those who went to fewer screenings. ${ }^{14}$ Their walking scores also increased at both the 12-week and 6 -month follow up points. In addition, patients who watched three or more videos also demonstrated better health-related quality of life at six months.

Theoretically, improvements in health outcomes occur when patients are better informed and more engaged in treatment decisions because they select treatments that fit better with their values and lifestyle, which improves their ability to adhere to treatment requirements. While more research is needed to verify these early correlations, these findings could be especially important for patients with lower health literacy, commonly elderly patients and those with lower education levels.

Historically, research on medical decision-making preferences has found that older patients and those with less formal education are less active and more likely to say they would defer to physicians for treatment choices than the average patient. ${ }^{15}$ Patients with these characteristics are also commonly associated with higher rates of hospitalization, ${ }^{16}$ poorer health outcomes, ${ }^{17}$ and increased mortality. ${ }^{18}$ Studies also demonstrate that they have a poorer understanding of their health conditions and are less engaged in treatment decisions. Not fully understanding one's treatment options can isolate patients and disengage them from participation in their care.

However, recent evidence from studies on SDM with decision aids suggests that with appropriately designed interventions, health literacy is not a barrier to improving patient activation and health outcomes. ${ }^{19}$ In a study of 187 patients with coronary artery disease in a safety-net practice at an urban medical center, patients with lower health literacy benefited as much 
as higher health literacy patients from an educational intervention using a SDM tool that focused on life style changes. ${ }^{20}$ Disease-specific knowledge improved in both groups, as did health behaviors and outcomes measured at six months, including improvement in diet and smoking habits. Other studies have explored the use of low literacy pamphlets, educational materials written at a fifth grade level, consent forms written at a seventh grade reading level, and different versions of a cervical cancer screening brochure (using either illustrated or bulleted text formats). ${ }^{21}$ Generally, materials developed for a lower literacy level demonstrated better results in lower literacy patients. The few studies that have examined the impact of low literacy interventions on health behaviors or outcomes produced mixed results. ${ }^{22}$ For instance, while one study of a dietary educational intervention demonstrated improved compliance with reduced caloric intake and saturated fat, ${ }^{23}$ other studies showed little effect on total caloric intake or cholesterol levels. The potential for SDM and decision aids to engage low health literacy patients in their treatment and improve their overall health outcomes necessitates additional study.

\section{Conclusion}

The National Quality Forum recently listed patient and family engagement (including SDM) as one of six health care reforms "with the greatest potential to eradicate disparities, reduce harm, and remove waste from the American healthcare system." ${ }^{24}$ Traditional informed consent methods have proven inadequate to engage and inform patients about treatment choices. The burdens of our current informed consent system weigh disproportionately on patients with low health literacy levels, who are often the oldest, sickest, and least educated. Ethically, we have an obligation to improve informed consent for all patients. This obligation further increases if we can demonstrate that the use of SDM could improve health outcomes for some of the most disadvantaged. While prior studies offer conflicting results on the impact of SDM on health outcomes, more recent research targeting disadvantaged patients suggests that SDM may positively affect the patient's decision-making process and health outcomes. While more research is needed to demonstrate these effects across a range of patient populations and conditions, SDM shows promise to engage patients at all levels of health literacy and improve overall health outcomes.

\section{References}

1. C. Lavelle-Jones, D. J. Byrne, and A. Cushieri, "Factors Affecting Quality of Informed Consent," BMJ 306, no. 6882 (1993): 885-890.
2. M. M. Bottrell, H. Alpert, R. L. Fishbach, L. L. Emmanuel, "Hospital Informed Consent Forms: Facilitating Quality Patient Physician Interaction," Archives of Surgery 135, no. 1 (2000): 26-33.

3. See Lavelle-Jones et al., supra note 1.

4. B. J. Zikmund-Fisher, M. P. Couper, E. Singer, C. A. Levin, F. J. Fowler, S. Ziniel, P. A. Ubel, and A. Fagerlin, "The DECISIONS Study: A Nationwide Survey of United States Adults Regarding 9 Common Medical Decisions," Medical Decision Making 30 (2010): 20S-34S.

5. A. Faigerlin, K. R. Sepucha, M. P. Couper, C. A. Levin, E. Singer, and B. J. Zikmund-Fisher, "Patients' Knowledge about 9 Common Health Conditions: The DECISIONS Survey," Medical Decision Making 30 (2010): 35S-52S.

6. $\quad I d$.

7. K. R. Sepucha, A. Faigerlin, M. P. Couper, C. A. Levin, E. Singer, and B. J. Zikmund-Fisher, Medical Decision Making 30 (2010): 77S-84S.

8. J. S. King and B. W. Moulton, "Rethinking Informed Consent: The Case for Shared Decision-Making," American Journal of Law छீ Medicine 32, no. 4 (2006): 429-501; R. M. Kaplan, "Shared Medical Decision Making: A New Tool for Preventative Medicine," American Journal of Preventative Medicine 26 (2003): 81.

9. A. M. O'Connor, C. L. Bennett, D. Stacey, and M. Barry et al., "Decision Aids for People Facing Health Treatment or Screening Decisions," Cochrane Database of Systematic Revieres 3 (2009), available at <http://decisionaid.ohri.ca/cochsystem. html $>$ (last visited November 15, 2010).

10. A. E. Volandes, M. K. Paasche-Orlow, and M. J. Barry et al., "Video Decision Support Tool for Advance Care Planning in Dementia: Randomised Controlled Trial," BMJ 338 (2009): b2159; C. D. Meade, W. P. McKinney, and G. P. Barnas, "Educating Patients with Limited Literacy Skills: The Effectiveness of Printed and Videotaped Materials About Colon Cancer," American Journal of Public Health 84, no. 1 (1994): 119-1121; T. C. Davis, H. J. Berkel, C. L. Arnold, I. Nandy, R. H. Jackson, and P. W. Murphy, "Intervention to Increase Mammography Utilization in a Public Hospital," Journal of General Internal Medicine 13, no. 4 (1998): 230-2333.

11. M. H. Eckman, R. Wise, A. C. Leonard, E. Dixon, C. Burrows, F. Khan, and E. Warm, "Impact of Health Literacy on Outcomes and Effectiveness of An Educational Intervention in Patients with Chronic Diseases," Journal of General Internal Medicine (under review, 2010); D. L. Frosch, K. J. Singer, and S. Timmermans, "Conducting Implementation Research in Community-Based Primary Care: A Qualitative Study on Integrating Patient Decision Support Interventions for Cancer Screening into Routine Practice," Health Expectations (November 10, 2009).

12. See O'Connor et al., supra note 9.

13. J. H. Hibbard, E. Peters, and A. Dixon et al., "Consumer Competencies and the Use of Comparative Quality Information: It Isn't Just about Literacy," Medical Care Research and Revierw 64, no. 4 (2007): 379-394; E. Guadagnoli and P. Ward, "Patient Participation in Decision-Making," Social Science Medicine 47, no. 3 (1998): 329-339; S. H. Kaplan et al., "Assessing the Effects of Physician-Patient Interactions on the Outcomes of Chronic Disease," Medical Care 27, no. 3 (1989): S110-S127; P. Mendonca and S. Brehm, "Effects of Choice on Behavioral Treatment of Overweight Children," Journal of Social Clinical Psychology 1, no. 4 (1983): 343-358; B. A. Schulman, "Active Patient Orientation and Outcomes in Hypertensive Treatment," Medical Care 17, no. 3 (1979): 267-280.

14. See Frosch et al., supra note 11.

15. N. K. Arora and C. A. McHorney, "Patient Preferences for Medical Decisions Making: Who Really Wants to Participate?" Medical Care 38, no. 3 (2000): 335-341; R. B. Deber, N. Kraetschmer, and J. Irvine, "What Role Do Patients Wish to Play in Treatment Decision Making?" Archives of Internal Medicine 156 (1996): 1414-1420; W. Levinson, A. Kao, A. 
Kuby, and R. A. Thisted, "Not all Patients Want to Participate in Decision Making," JGIM 20 (2005): 531-535.

16. D. A. Dewalt, N. D. Berkman, S. Sheridan, K. N. Lohr, and M. P. Pignone, "Literacy and Health Outcomes: A Systematic Review of the Literature," Journal of General Internal Medicine 19, no. 12 (2004): 1228-1239; M. V. Williams, R. M. Parker, and D. W. Baker et al., "Inadequate Functional Health Literacy among Patients at Two Public Hospitals," JAMA 274, no. 21 (1995): 1677-1682.

17. S. C. Kalichman and D. Rompa, "Functional Health Literacy Is Associated with Health Status and Health-Related Knowledge in People Living with HIV-AIDS," Journal of Acquired Immune Deficiency Syndromes 25, no. 4 (2000): 337-344; R. L. Sudore, K. Yaffe, and S. Satterfield et al., "Limited Literacy and Mortality in the Elderly: The Health, Aging, and Body Composition Study, Journal of General Internal Medicine 21, no. 8 (2006): 806-812; B. D. Weiss, G. Hart, D. L. McGee, and S. D'Estelle, "Health Status of Illiterate Adults: Relation Between Literacy and Health Status among Persons with Low Literacy Skills," Journal of American Board of Family Practice 5, no. 3 (1992): 257-264; M. S. Wolf, J. A. Gazmararian, and D. W. Baker, "Health Literacy and Functional Health Status among Older Adults," Archives of Internal Medicine 165, no. 17 (2005): 1946-1952.

18. D. W. Baker, M. S. Wolf, J. Feinglass, J. A. Thompson, J. A. Gazmararian, and J. Huang, "Health Literacy and Mortality among Elderly Persons," Archives of Internal Medicine 167, no. 14 (2007): 1503-1509.

19. See Eckman, supra note 11; Frosch, supra note 11.

20. See Eckman, supra note 11.

21. T. C. Davis, J. A. Bocchini, Jr., and D. Fredrickson et al., "Parent Comprehension of Polio Vaccine Information Pamphlets," Pediatrics 97, no. 6, Pt. 1 (1996): 804-810; M. L. Eaton and R. L. Holloway, "Patient Comprehension of Written Drug Information," American Journal of Hospital Pharmacy 37, no. 2 (1980): 240-243; T. C. Davis, R. F. Holcombe, H. J. Berkel,
S. Pramanik, and S. G. Divers, "Informed Consent for Clinical Trials: A Comparative Study of Standard versus Simplified Forms," Journal of National Cancer Institute 90, no. 9 (1998): 668-674; R. Michielutte, J. Bahnson, M. B. Dignan, and E. M. Schroeder, "The Use of Illustrations and Narrative Text Style to Improve Readability of a Health Education Brochure," Journal of Cancer Education 7, no. 3 (1992): 251-260.

22. E. A. Coleman, S. Coon, and C. Mohrmann et al., "Developing and Testing Lay Literature about Breast Cancer Screening for African American Women," Clinical of Journal Oncological Nursing 7, no. 1 (2003): 66-71; M. A. Winkleby, B. Howard-Pitney, C. A. Albright, B. Bruce, H. C. Kraemer, and S. P. Fortmann, "Predicting Achievement of a Low-Fat Diet: A Nutrition Intervention for Adults with Low Literacy Skills," Preventative Medicine 26, no. 6 (1997): 874-882; L. C. Hussey, Minimizing, "Effects of Low Literacy on Medication Knowledge and Compliance among the Elderly," Clinical Nursing Research 3, no. 2 (1994): 132-145; P. W. Murphy, T. C. Davis, E. J. Mayeaux, T. Sentell, C. Arnold, and C. Rebouche, "Teaching Nutrition Education in Adult Learning Centers: Linking Literacy, Health Care, and the Community, Journal of Community Health Nursing 13, no. 3 (1996): 149-158; T. J. Hartman, P. R. McCarthy, R. J. Park, E. Schuster, L. H. Kushi, "Results of a Community-Based Low-Literacy Nutrition Education Program," Journal of Community Health 22, no. 5 (1997): 325341; S. K. Kumanyika, L. Adams-Campbell, and B. Van Horn et al., "Outcomes of a Cardiovascular Nutrition Counseling Program in African-Americans with Elevated Blood Pressure or Cholesterol Level," Journal of the American Diet Association 99, no. 11 (1999): 1380-1391.

23. B. Howard-Pitney, M. A. Winkleby, C. L. Albright, B. Bruce, and S. P. Fortmann, "The Stanford Nutrition Action Program: A Dietary Fat Intervention for Low-Literacy Adults," American Journal of Public Health 87, no. 12 (1997): 1971-1976.

24. See Zikmund-Fisher et al., supra note 4. 